\title{
STUDY OF TRANSONIC EFFECT OF FLOWS AROUND SLENDER BODIES OF REVOLUTION AND PLANE PROFILES
}

\author{
Hoang Thi Bich Ngoc \\ Hanoi University of Technology
}

\begin{abstract}
Transonic effect with presence of local supersonic terminated by shock wave is not wished. In spite of wishes or not, the appearance of shock waves is not avoided. Strong shock waves cause losses, even a grand decrease of aerodynamic quality in fluid-solid interaction. However, under certain conditions, transonic effect increases the drag and at the same time increases the lift leading the amelioration of aerodynamic quality. This work uses numerical methods and established programs for solving differential equations of the axisymmetric flow and the plane flow to study the influence of transonic effects for the two cases.
\end{abstract}

\section{INTRODUCTION}

Shock wave is a special phenomenon for supersonic flows. Transonic flows include supersonic regions, so the shock wave is a phenomenon usually attached to transonic flows. Properties of shock wave depend on the geometry and free Mach number. For the same main section, transonic effects are very much different between plane flow and flow of revolution. With the hypothesis of potential flow, the calculation of flows around slender bodies of revolution is carried out by solving small disturbance potential equations. Numerical results of the established program are compared with published experimental and numerical results.

For flows around plane profiles, transonic effect attached shock wave much stronger than transonic effect in axisymmetric flows under the same conditions. Therefore, the small disturbance method is not adequate for plane flows. In this case, solving full potential equations is used. Numerical results of established program are compared with experimental results. This work uses also the Fluent software to calculate transonic flows. Numerical results calculating from the established program and results of Fluent are compared each other.

\section{NUMERICAL METHODS}

\subsection{Transonic flow around slender bodies of revolution}

The problem of slender axisymmetric transonic flow is solved by using small disturbance method with aerodynamic bodies having maximum thickness ratios less than $10 \%$ 
and without incidence. The full potential equation for the axisymmetric flow is written in cylindrical coordinate system [1]:

$$
\left(a^{2}-u^{2}\right) \Phi_{x x}+\left(a^{2}-v^{2}\right) \Phi_{r r}+\frac{a^{2}}{r} \Phi_{r}-2 u v \Phi_{x r}=0
$$

where $\Phi$ is velocity potential function, $u=\Phi_{x} ; v=\Phi_{r} ; a$ is velocity of sound.

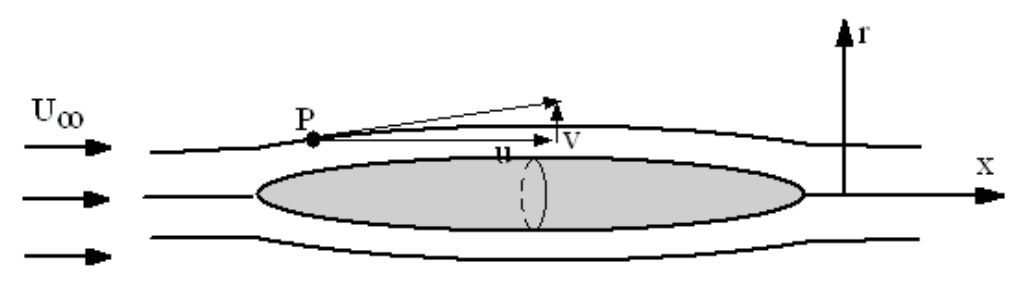

Fig. 1. Axisymmetric flow

Conditions of small disturbance for velocities are written as: $u=U_{\infty}+u^{\prime} ; v=$ $0+v^{\prime}=v^{\prime}$

$\left(u^{\prime}\right.$ and $v^{\prime}$ are disturbance velocities in the directions $\mathrm{x}$ and $\mathrm{r}$ )

$$
\Phi=x \cdot U_{\infty}+\varphi
$$

where $\varphi$ is disturbance velocity potential function: $\frac{\partial \varphi}{\partial x}=u^{\prime} ; \frac{\partial \varphi}{\partial r}=v^{\prime}$ The small disturbance potential equations is written as follows:

$$
\left(a^{2}-u^{2}\right) \frac{\partial^{2} \varphi}{\partial x^{2}}-2 u v \frac{\partial^{2} \varphi}{\partial x \partial r}+\left(a^{2}-v^{2}\right) \frac{\partial^{2} \varphi}{\partial r^{2}}+\frac{a^{2}}{r} \varphi_{r}=0
$$

Using the Mach number M, the equation (4) becomes:

$$
\left[1-M_{\infty}^{2}-(\gamma+1) M_{\infty}^{2}\left(\frac{\varphi_{x}}{U_{\infty}}\right)\right] \varphi_{x x}+\frac{1}{r}\left(r \varphi_{r}\right)_{r}=0
$$

where $\gamma$ is ratio of specific heats at constant pressure and constant volume $\gamma=c_{p} / c_{v}$.

The equation (4) with the boundary conditions of slip on the profile is solved by a method of finite differences. For flow in subsonic regions, the partial differential equation (4) is under the elliptic form, and in supersonic regions, this equation takes in the hypersonic form [2].

The equation (4) allows transforming from the elliptic form into the hyperbolic form and vice versa by using the following expression:

$$
\lambda=\beta^{2}-M_{\infty}^{2}(\gamma+1) \varphi_{x} ; \quad \beta^{2}=1-M_{\infty}^{2}
$$

\subsection{Transonic flow around plane profiles}

Disturbances of plane flow are very much stronger than those of axisymmetric flow, and thus, the small disturbance method is conveniently applied only to plane profiles having thickness less than $6 \%$. Transonic flow problem for a plane profile is thus treated 
by solving the full potential equation. For two-dimensional flow, the full potential equation is written in Cartesian coordinate system [1]:

$$
\left[a^{2}-\left(\frac{\partial \Phi}{\partial x}\right)^{2}\right] \frac{\partial^{2} \Phi}{\partial x^{2}}+\left[a^{2}-\left(\frac{\partial \Phi}{\partial y}\right)^{2}\right] \frac{\partial^{2} \Phi}{\partial y^{2}}-2\left(\frac{\partial \Phi}{\partial x}\right)\left(\frac{\partial \Phi}{\partial y}\right) \frac{\partial^{2} \Phi}{\partial x \partial y}=0
$$

In the case of symmetric geometry and cinematic, the boundary conditions for the equation (6) are the condition of slip on profile and the disturbance is negligible at the infinity. The equation (6) is solved on a grid of finite differences. A center diagram is used for an elliptic region (Fig. 2), and two-step diagram for a hyperbolic region (Fig. 3).
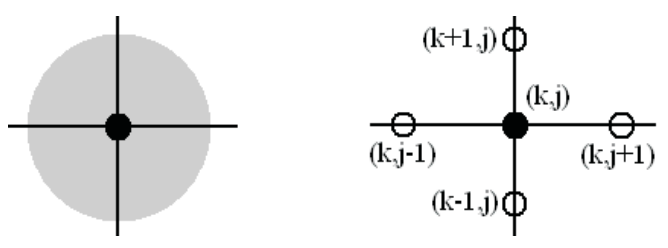

Fig. 2. Difference in elliptic region

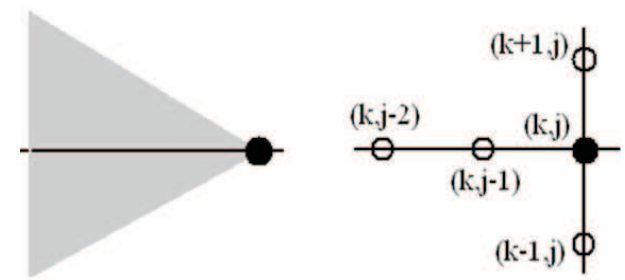

Fig. 3. Difference in hyperbolic region

Being different from the small disturbance method, the full potential equation problem requires a grid much more complex. In this work, the grid is generated by using two methods: iterating the Laplace's equation and mapping transformation.



Fig. 4. Process of grid generation for parabolic-arc profile $\mathrm{L} / \mathrm{D}=10$ - results from established program using mapping transformation 
Fig. 4 presents grids generated by using mapping transformation method for parabolicarc profile of fineness $\mathrm{L} / \mathrm{D}=10$ ( $\mathrm{L}$ and $\mathrm{D}$ are the length and the maximum diameter of profile). The constant of transformation and the fineness of grid are given in interface for users conveniently regulating.

If $z$ is complex function: $z=f(\xi)$ with $z=x+i y$ and $\xi=r e^{i \theta}$, we can use an expression of mapping transformation of Karman-Treeft as follows:

$$
\frac{\xi-1}{\xi+1}=\left(\frac{z-a_{0}}{z-a}\right)^{\frac{\pi}{\beta}}
$$

where $\mathrm{a}$ is the coordinate of trailing edge in the complex surface, $\beta$ is the outer angle of trailing edge, $a_{0}$ is the constant depended on the profile.

The boundary conditions on physics plane $(\mathrm{x}, \mathrm{y})$ are written as:

$$
\frac{v}{u}=\frac{\Phi_{y}}{\Phi_{x}}=\left.\frac{d F}{d x}\right|_{\text {surface }}
$$

where $F$ is surface geometry.

In the transformation plane $(\xi, \eta)$, the expression (8) becomes:

$$
\Phi_{x}=\varphi_{\xi} \xi_{x}+\varphi_{\eta} \eta_{x}+V_{\infty} ; \quad \Phi_{y}=\varphi_{\xi} \xi_{y}+\varphi_{\eta} \eta_{y}
$$

and

$$
\Phi_{\xi}\left(\xi_{x} \eta_{\xi}+\xi_{y} \eta_{y}\right)+\Phi_{\eta}\left(\eta_{x}^{2}+\eta_{y}^{2}\right)+V_{\infty} \eta_{x}=0
$$

The boundary conditions at infinite boundary, for the problem without lift, $\varphi=0$; for the problem with lift, $\varphi=\frac{\Gamma}{2 \pi} \operatorname{arctg}\left(\sqrt{1-M_{\infty}^{2}} \frac{y}{x}\right)$.

\subsection{Using Fluent software}

Numerical results of established program can be compared with experimental results and results calculated by using Fluent software.

For transonic flow, the use of Fluent software to obtain good results is not simple. This requires knowledge of physics and numerical treatments... In the report, we show results and do not present the process of numerical treatment for Fluent software.

\section{NUMERIACAL RESULTS AND COMPARISON}

\subsection{Comparion of results for transonic flow around slender bodies of revolution}

In Fig. 5 are presented numerical results on pressure coefficients computed from the code established by using small disturbance method (SDM) for parabolic-arc profiles having $\mathrm{L} / \mathrm{D}=14$ and $\mathrm{L} / \mathrm{D}=12$, free Mach number $M_{\infty}=1$. The comparison of present numerical results with experimental result of R. A. Taylor and J. B. McDevitt [3] shows a similarity. Fig. 6 presents the comparison of numerical results computed from established program and numerical results of $\mathrm{F}$. R. Bailey [4] for parabolic-arc profile of $\mathrm{L} / \mathrm{D}=10$ with free Mach numbers $M_{\infty}=0.99$ and $M_{\infty}=1$ (no sting and with sting). 

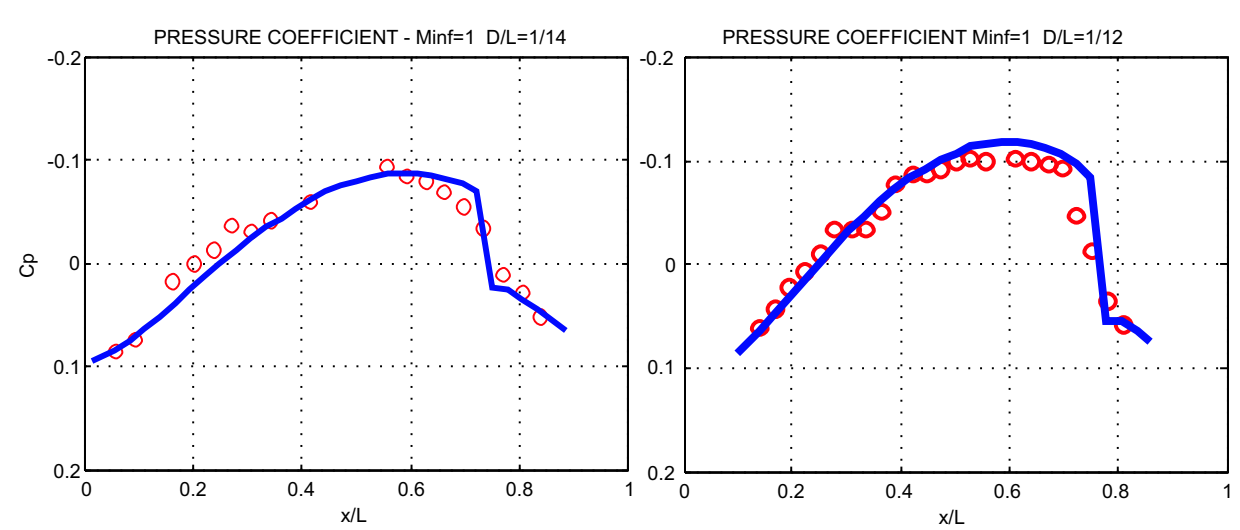

Fig. 5. Pressure coefficient - Parabolic-arc 3D of revolution $\mathrm{L} / \mathrm{D}=14$ and $\mathrm{L} / \mathrm{D}=12 ; \mathrm{M}_{\infty}=1$

(Comparison of present numerical results and experimental results [3])
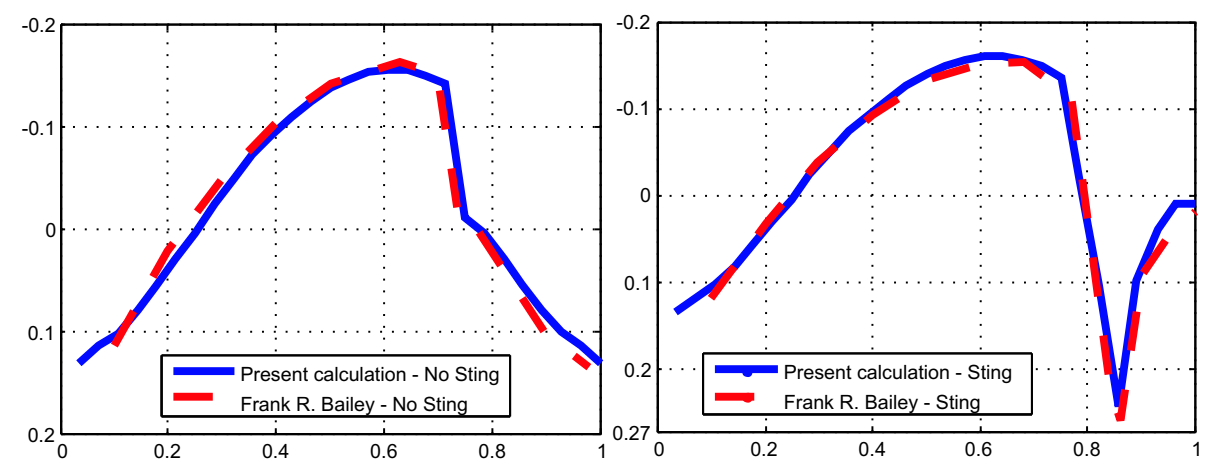

Fig. 6. Pressure coefficient - Parabolic-arc 3D of revolution $\mathrm{L} / \mathrm{D}=10, \mathrm{M}_{\infty}=0.99$ and $\mathrm{M}_{\infty}=1$

(Comparison of present numerical results and numerical results of F. R. Bailey [4])

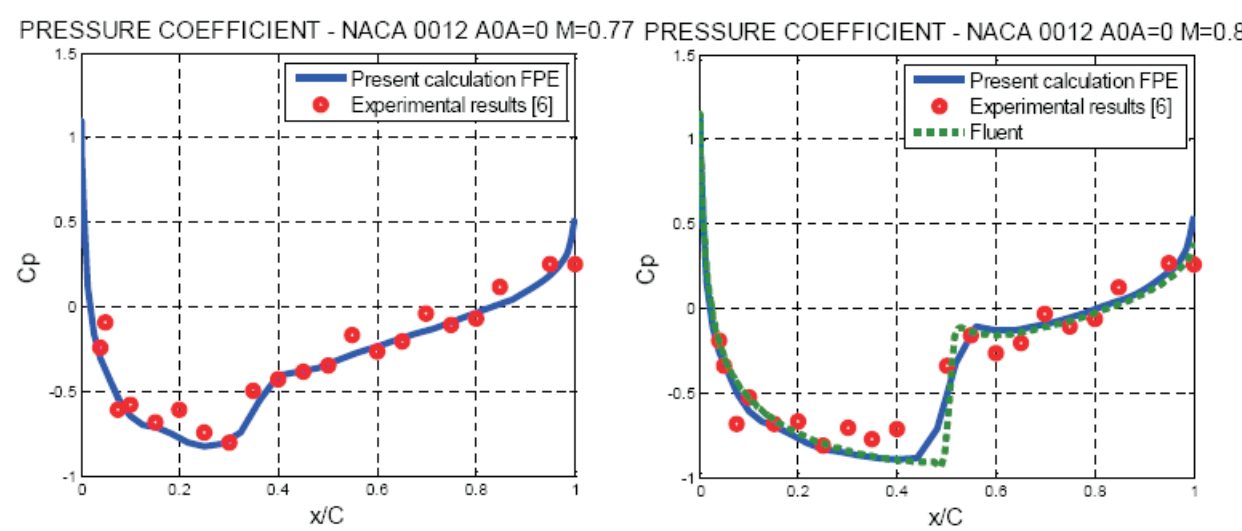

Fig. 7. Pressure coefficient - Profile Naca $0012 ; \mathrm{M}_{\infty}=0.77$ and $\mathrm{M}_{\infty}=0.8$ (Comparison of present numerical results FPE and experimental results [6])

\subsection{Comparison of results for transonic flow around plane profiles}

For plane flow, disturbances caused by transonic effect are very strong, the small disturbance method is thus only applicable to very thin profiles having the thickness less than 
$6 \%(\mathrm{~L} / \mathrm{D}>17)$. The full potential equation (FPE) method [5] permits to calculate transonic flows with rather strong shock waves $\left(\mathrm{M}_{\max } \leq 1.4\right)$. Numerical results computed from the code established are compared with experimental results and results calculated by using Fluent software.

Fig. 7 shows results of pressure coefficients on profile Naca $0012, \mathrm{M}_{\infty}=0.77$ and $\mathrm{M}_{\infty}=0.8$ with the comparison of present numerical results (FPE program) and experimental results [6], and results calculated from Fluent software. Fig. 8 shows results on pressure coefficients computed by our present program FPE in comparison with results calculated from Fluent software for parabolic-arc profile having the thickness 10\% (L/D=10), $\mathrm{M}_{\infty}=0.84$ and $\mathrm{M}_{\infty}=0.85$.

The above comparisons show that the programs established by solving the small disturbance potential equation for slender bodies of revolution and the full potential equation for plane profiles are accurate. This allows calculating and studying different cases to deduce differences of transonic effects between the axisymmetric flow and the phane flow.
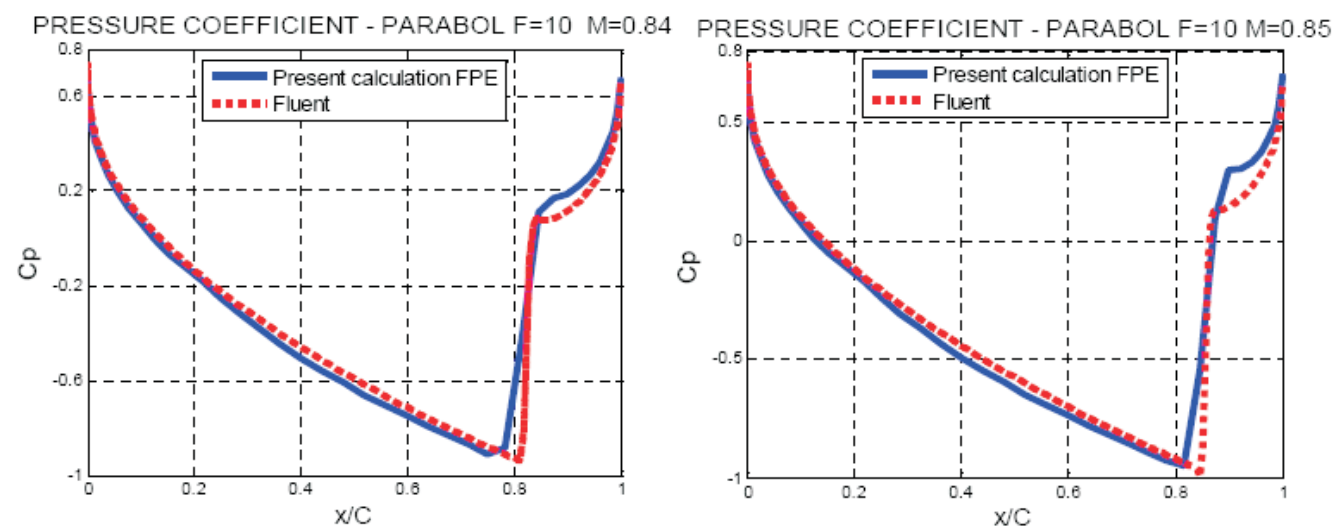

Fig. 8. Pressure coefficient - Parabolic-arc pfofile $\mathrm{L} / \mathrm{d}=10 ; \mathrm{M}_{\infty}=0.84$ and $\mathrm{M}_{\infty}=0.85$ (Comparison of present numerical results FPE and results of Fluent) )

\section{TRANSONIC EFFECTS FOR THE AXISYMMETRIC FLOW AND THE PLANE FLOW}

Using the established programs, we can calculate aerodynamic parameters of transonic flows around slender bodies of revolution and plane profiles with the same main section and the same kinetic conditions. Fig. 9 persents iso-Mach lines and Mach field of flows having free Mach number $\mathrm{M}_{\infty}=0.85$ around parabolic-arc profile $\mathrm{L} / \mathrm{D}=10$ for two cases: axisymmetric and plane. Results of plane case are computed from established program FPE (full potential equation) and those of axisymmetric case from established program SDM (small disturbance method). The comparison of results of the two cases shows a great difference between them. For the plane flow, local supersonic region is occupied more half of profile contour and rather strong shock wave appears at the adimensional absciss $\mathrm{x} / \mathrm{L}=0.78$, maximum Mach number $\mathrm{M}_{\max }=1.38$. However, for the axisymmetric 
flow, there is not a supersonic region and maximum Mach number $\mathrm{M}_{\max }=0.9$. Numerical distributions of pressure coefficient on the contour of the two cases are presented in Fig. 10
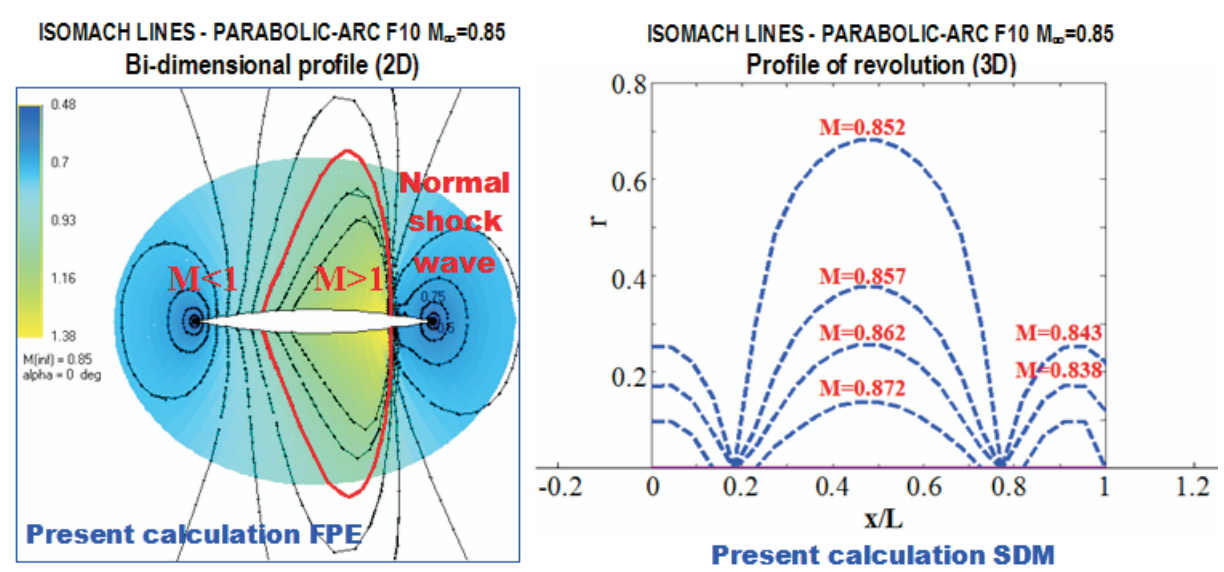

Fig. 9. Iso-Mach lines - Parabolic-arc profile $\mathrm{f} 10, \mathrm{M}_{\infty}=0.85$

Plane flow (established program FPE) and axisymmetric flow (SDM)

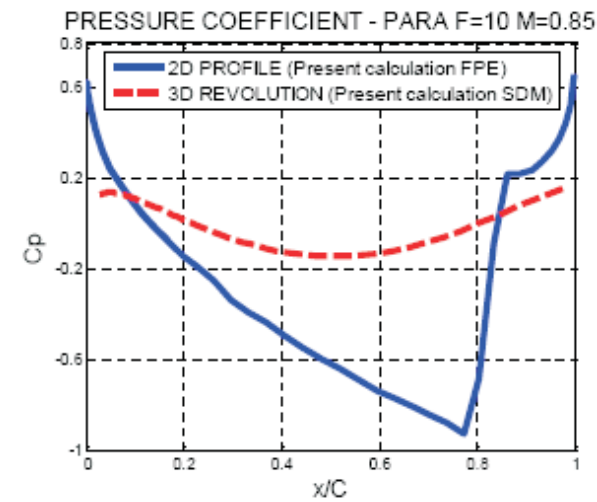

Fig. 10. Pressure coefficient - Parabolic-arc f10, $\mathrm{M}_{\infty}=0.85(2 \mathrm{D}$ and $3 \mathrm{D}$ of revolution)

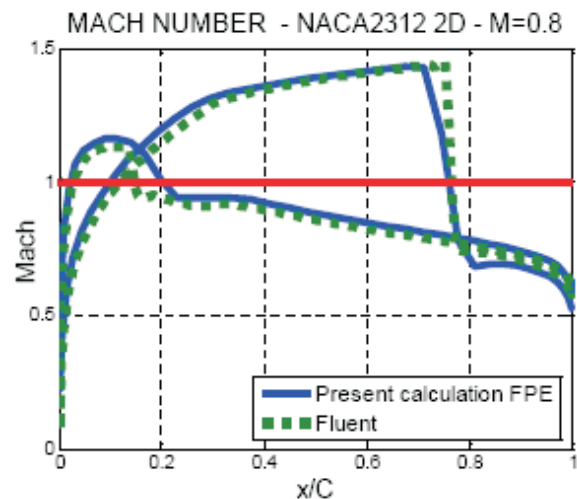

Fig. 11. Mach number - Profile Naca 2312; $\mathrm{M}_{\infty}=0.8$ (Comparison of present numerical results FPE and result Fluent)

At $\mathrm{M}_{\infty}=1$, shock waves of the plane case are very strong, the FPE method is not satisfied with the hypothesis $\mathrm{M}_{\max } \leq 1.4$, and we can use results of Fluent for the analyzation. In order to assure the accuracy of operating results of Fluent, it is necessary to have comparisons between results of Fluent and others (as compared with those of FPE program in Figs. 7 and 8). Fig. 11 shows the comparison of results calculated by Fluent and by FPE on the Mach number distribution in case of $\mathrm{M}_{\max }=1.4$ (profile Naca 2312, $\mathrm{M}_{\infty}=0.8$ ). These comparisons permit to use results of Fluent at $\mathrm{M}_{\infty}=1$ in Fig. 12 and 13.

In Fig. 11 and 12 are presented results on Mach filed and iso-Mach lines for parabolic$\operatorname{arc}$ profile $\mathrm{L} / \mathrm{D}=12$ with free Mach number $\mathrm{M}_{\infty}=1$. At the free Mach number $\mathrm{M}_{\infty}=1$, flow 

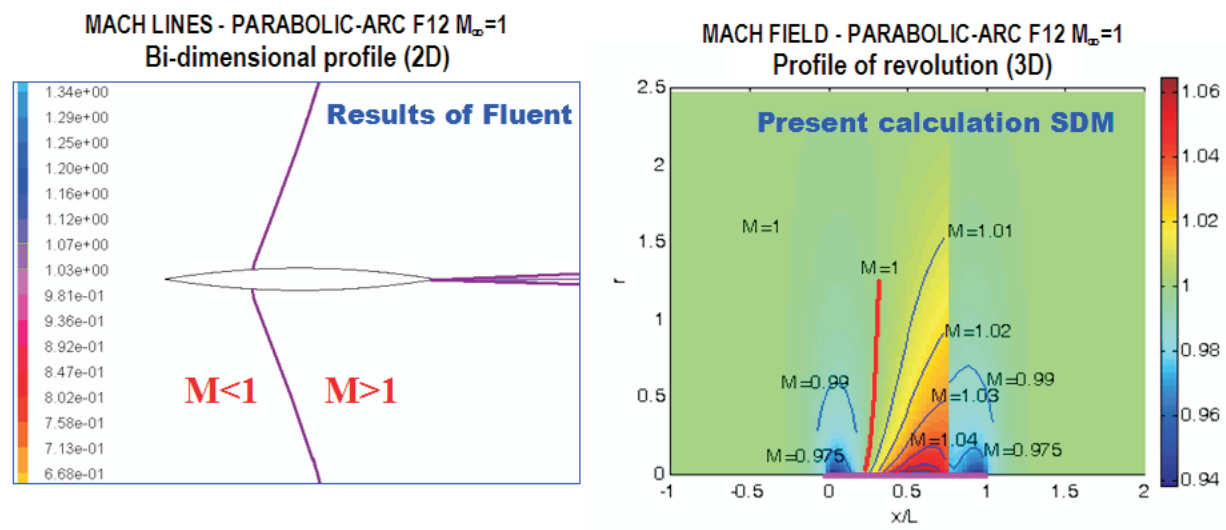

Fig. 12. Iso-Mach lines and Mach field - Parabolic-arc profile f12, $\mathrm{M}_{\infty}=1$ Plane profile (Fluent) and axisymmetric profile (established program SDM)
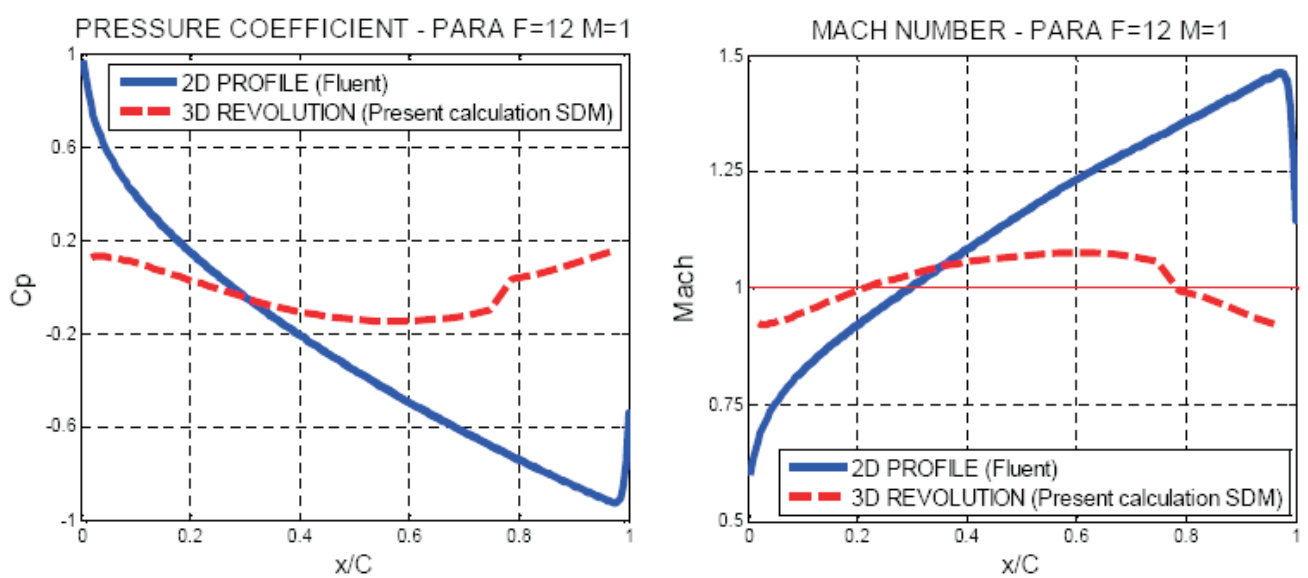

Fig. 13. Pressure coefficient and Mach number Parabolic-arc profile $\mathrm{f} 12, \mathrm{M}_{\infty}=1$ (2D and $3 \mathrm{D}$ of revolution)

becomes instable for the plane profile; supersonic region do not be finished on the contour; normal shock wave disappears and oblique shock wave is produced at trailing edge with the strength depended on the geometry of profile. We can see in Fig. 12, there is a great difference of plane case and axisymmetric case. For the two-dimensional flow, a great supersonic region is developed until wake with maximum Mach number $\mathrm{M}_{\max }=1.47$ and there is not normal shock wave. While for the axisymmetric flow, maximum Mach number $\mathrm{M}_{\max }=1.06$ and supersonic region is finished by a weak shock wave on the contour of body. Numerical results on pressure coefficient and Mach number are presented in Fig. 13, for the plane flow calculated from Fluent and for the axisymmetric flow computed from established program SDM.

Fig. 14 shows numerical results on pressure coefficient and Mach number of flows having free Mach number $\mathrm{M}_{\infty}=0.95$ around parabolic-arc profile of fineness $\mathrm{L} / \mathrm{D}=10$ and 

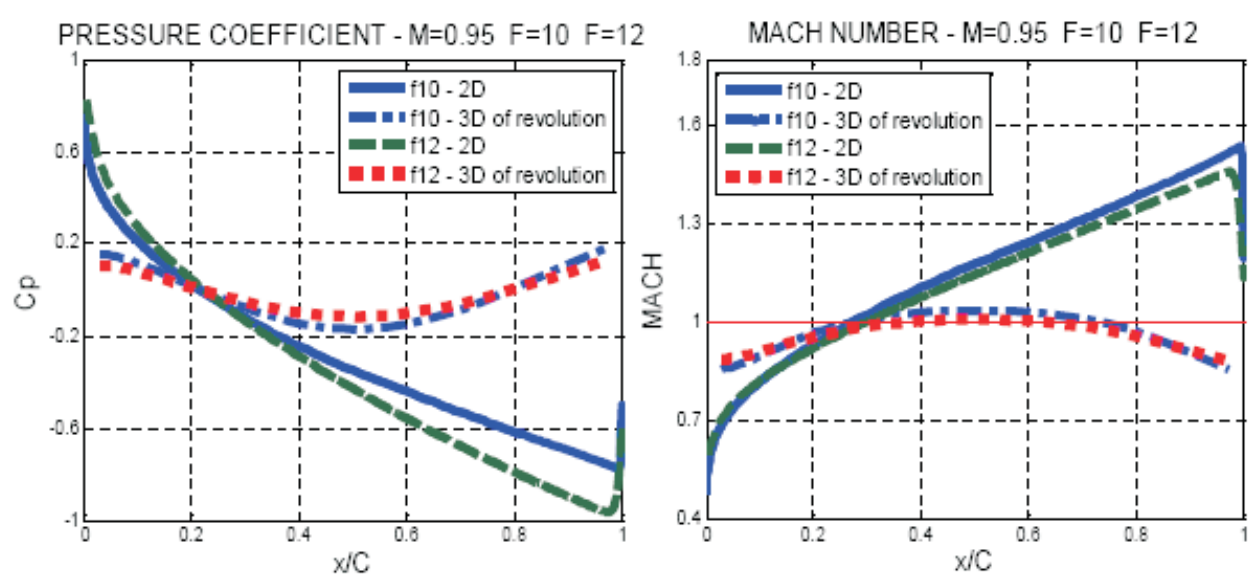

Fig. 14. Pressure coefficient and Mach number Parabolic-arc profile f10 and f12 $\mathrm{M}_{\infty}=0.95$ (2D and 3D of revolution)

$\mathrm{L} / \mathrm{D}=12$. With this free Mach number, the aerodynamic characteristics are not very different between two profiles of thickness $10 \%$ and $8.3 \%$. However, there is a clear difference for the plane flow and the axisymetric flow. For tri-dimensional of revolution cases of profile f10 and f12, maximum Mach number reach values $\mathrm{M}_{\max }=1.02$ and $\mathrm{M}_{\max }=1.01$; and at these maximum Mach number, there are not shock waves. While for two-dimensional of profile f10 and f12, maximum Mach number have very big values $\mathrm{M}_{\max }=1.55$ and $\mathrm{M}_{\max }=1.47$, and with very great supersonic regions, normal shock waves are transform into oblique shock waves at trailing edges. These plane flows are very instable. If we return in Fig. 9 of plane flow with the free Mach number $\mathrm{M}_{\infty}=0.85$ around profile $\mathrm{f10}$, we can see a strong normal shock wave appeared on profile. The flow is stable and is use to be taken for civil airplanes.

\section{DISCUSSION AND CONCLUSION}

The calculation of transonic flow is a very complex problem. That is a type of mixed flows including supersonic regions and subsonic regions in disturbance domain. The partial differential equation of movement has transformations from elliptic - parabolic - hyperbolic and vice versa. Specially, when there is an appearance of shock wave, which causes a discontinuity of flow parameters. All these questions are treated in the discretisation of equation, the grid generation and the establishment of algorithm for programming the codes of the plane flow and the axisymmetric flow. Numerical results are compared with experimental results and other published numerical results. Beside, we also realize the calculation by using Fluent software to verify each other numerical results.

An airplane or a missile has wings producing lift or realizing the control, fuselage and some parts having forms of revolution (inlet of engine...). The calculated results and the analyses show that the transonic effect for the flow around slender bodies appears much more tardily and weakly than for the flow around wings. For slender bodies of revolution, strongest normal shock waves happen with the flow having free Mach number around the unity $M_{\infty}=1 \pm 0.01$. With these Mach numbers, the flow around wings is instable and is 
usually existed in certain conditions, but not used to design regimes, and this is regimes that have maximum losses for the flow around bodies of revolution. The band of Mach numbers applied to wings giving the best efficiency is $M_{\infty}=0.7 \div 0.85$ [7], which do not cause the transonic effect for the flow around bodies of revolution. The impacts of transonic effect are considered for the main wings, the wings of control (flag, aileron....), and the blades in turbo-machines of engine (fans, compressors, turbines).

The validated built programs permit to calculate different cases in order to deduce application significations also to expand the theory of transition flows, especially this type of flows is not well-known in Vietnam.

\section{REFERENCES}

[1] Courant R, Friedrichs K. O., Supersonic flow and shock waves, Springr-Verlag Ed. New York - Heidelberg - Berlin, 1999.

[2] Hoang Thi Bich Ngoc, Tran Thanh Tung, Program for calculation of transonic flows around slender bodies of revolution, Proceeding of National Conferences on Engineering Mechanics 2 (2007) 367-378, Hanoi.

[3] Robert A. Taylor and John B. McDevitt, Pressure distributions at transonic speeds for parabolic-arc bodies of revolution having fineness ratios of 10, 12, and 14, Ames Aeronautical Laboratory Moffett Field - NASA, USA, March 1958.

[4] Frank R. Bailey, Numerical calculation of transonic flow about slender bodies of revolution, NASA technical note, USA, December 1971

[5] Hoang Thi Bich Ngoc, Le Hong Chuong, Numerical calculation of transonic flows by solving full potential equation, Proceeding of National Conferences on Engineering Mechanics 2 (2006) 171-180, Hanoi.

[6] Riegels F. W., Aerofoil section - Results from wind-tunnel investigations, Butterworths Ed. London, 1961

[7] Hoang Thi Bich Ngoc, Influences of the compressibility on aerodynamic characteristics of profile under the transonic flow theory, Vietnam Journal of Mechanics 29 (4) (2007) 497-506.

Received January 05, 2009

\section{NGHIÊN CỨU HIÊU ỨNG QUÁ Đô ÂM CỦA DÒNG QUA THÂN MẢNH TRÒN XOAY ĐỐI XỨNG TRỤC VÀ PROFIL PHẲNG}

Hiệu ứng quá độ âm với sự xuất hiện vùng trên âm cục bộ kết thúc bằng sóng va là điều không mong muốn. Nhưng dù muốn hay không muốn, sự có mặt của sóng va là không thể tránh khỏi. Cường độ sóng va mạnh sẽ gây nên những tổn thất lớn, thậm chí làm sụt giảm mạnh chất lượng khí động của tương tác khí động khí-rắn. Tuy nhiên, trong một phạm vi nào đó, hiệu ứng quá độ âm làm tăng lực cản nhưng đồng thời cũng làm tăng mạnh lực nâng làm cho chất lượng khí động được cải thiện rõ rệt. Nghiên cứu ở đây sử dụng phương pháp số lập trình giải phương trình vi phân chuyển động đối với bài toán dòng qua thân mảnh tròn xoay và profil phẳng để nghiên cứu ảnh hưởng khác nhau của hiệu ứng quá độ âm đối với hai trường hợp này. 